\title{
HEART RATE VARIABILITY (HRV) AND MUSCULAR SYSTEM ACTIVITY (EMG) IN CASES OF CRASH THREAT DURING SIMULATED DRIVING OF A PASSENGER CAR
}

\author{
KRYSTYNA ZUŻEWICZ ${ }^{1}$, DANUTA ROMAN-LIU ${ }^{1}$, MARIA KONARSKA ${ }^{1}$, PAWEŁ BARTUZI ${ }^{1}$, \\ KRZYSZTOF MATUSIAK ${ }^{2,3}$, DARIUSZ KORCZAK ${ }^{4}$, ZBIGNIEW LOZIA ${ }^{5}$, and MAREK GUZEK ${ }^{5}$ \\ ${ }^{1}$ Central Institute for Labour Protection, National Research Institute, Warszawa, Poland \\ Department of Ergonomics \\ ${ }^{2}$ Warsaw University of Technology, Warszawa, Poland \\ Faculty of Power and Aeronautical Engineering \\ ${ }^{3}$ CRASh s.c. - Computer Research for Automotive Safety, Warszawa, Poland \\ ${ }^{4}$ Medical University of Warsaw, Warszawa, Poland \\ Department of Internal Medicine and Cardiology \\ ${ }^{5}$ Warsaw University of Technology, Warszawa, Poland \\ Faculty of Transport
}

\begin{abstract}
Objectives: The aim of the study was to verify whether simultaneous responses from the muscular and circulatory system occur in the driver's body under simulated conditions of a crash threat. Materials and Methods: The study was carried out in a passenger car driving simulator. The crash was included in the driving test scenario developed in an urban setting. In the group of 22 young male subjects, two physiological signals - ECG and EMG were continuously recorded. The length of the RR interval in the ECG signal was assessed. A HRV analysis was performed in the time and frequency domains for 1-minute record segments at rest (seated position), during undisturbed driving as well as during and several minutes after the crash. For the left and right side muscles: $m$. trapezius (TR) and $m$. flexor digitorum superficialis (FDS), the EMG signal amplitude was determined. The percentage of maximal voluntary contraction (MVC) was compared during driving and during the crash. Results: As for the ECG signal, it was found that in most of the drivers changes occurred in the parameter values reflecting HRV in the time domain. Significant changes were noted in the mean length of RR intervals (mRR). As for the EMG signal, the changes in the amplitude concerned the signal recorded from the FDS muscle. The changes in ECG and EMG were simultaneous in half of the cases. Conclusion: Such parameters as mRR (ECG signal) and FDS-L amplitude (EMG signal) were the responses to accident risk. Under simulated conditions, responses from the circulatory and musculoskeletal systems are not always simultaneous. The results indicate that a more complete driver's response to a crash in road traffic is obtained based on parallel recording of two physiological signals (ECG and EMG).
\end{abstract}

Key words:

Heart rate variability, Electromyography, Driving simulator, Crash

This research was partially supported by the Central Institute for Labour Protection, National Research Institute, Warszawa, Poland and APROSYS - Integrated Project on Advanced Protection Systems, EC 6th Framework Program, contract: TIP3-CT-2004-506503, 2004-2009 carried out at the Warsaw University of Technology. Received: October 1, 2012. Accepted: September 19, 2013.

Corresponding author: K. Zużewicz, Department of Ergonomics, Central Institute for Labour Protection - National Research Institute, Czerniakowska 16, 00-701 Warszawa, Poland (e-mail: krzuz@ciop.pl). 


\section{INTRODUCTION}

Technical solutions, enabling the registration of physiological parameters in road transport drivers are sought to provide objective assessment of the driver's involvement in road accidents. They are essential for the staff determining who was at fault in the accident and for future calculation of compensation costs [1]. First of all, it should be established whether the driver was aware of the risk, whether they reacted to the dangerous event being the threat for other road users, and whether the driver's response was connected with the actions aimed at avoiding or reducing the consequences of the accident.

While performing such activities as vehicle driving, a man is exposed to various types of load, depending on the vehicle type and exposure to various risk factors. These factors negatively affect the driver's alertness level and thus the potential correct response to stress. They are significant under the threat of a road accident or crash and time deficit in decision making is an additional factor under these circumstances. According to the basic mechanisms of "acute" stress, the basic body response under threat involves activation of the circulatory and musculoskeletal system by the autonomic nervous system (ANS). Such response allows the person under threat to take prompt reflexive and conscious actions [2-4].

Muscle strength and maximal voluntary contraction (MVC) depend on muscle length (location of different parts of the body) [5], but not only. They also depend on individual traits as well as psychological and external loads. Among the noninvasive methods of muscle activity assessment, surface electromyography (EMG) is believed to be the most reliable one [5-9].

The circulatory system is a system which is sensitive to environmental stimuli. The functional condition of the autonomic nervous system (ANS) is mainly responsible for changes in HR. Constant "adjustment" of HR to changing environmental conditions involves mainly mutual relations (activation-inhibition) of the sympathetic and parasympathetic components $[10,11]$. Heart rate variability (HRV) analysis in the frequency domain allows for drafting a description of these changes, based on the RR interval sequence in the ECG signal $[12,13]$.

Daily activity of every human being involves a combination of physical and mental activities. Such combination also occurs during driving in road traffic. Both kinds of load - physical and mental - also evoke physiological responses, mediated by ANS and the endocrine system. They result in an increase in blood pressure, HR, cardiac output and skeletal muscle blood flow and a decrease in renal and visceral blood flow [14-17]. Such physiological changes can be explained by the need of limiting blood flow to visceral capillary beds and directing it to the body systems, which react to stress stimuli, namely the heart, brain and skeletal muscles.

The aim of this study was to analyze the responses from the musculoskeletal and circulatory systems in drivers during simulated sudden road accidents. Therefore, an attempt was made to answer the question whether simultaneous responses from the musculoskeletal and circulatory systems occur under a threat of a crash. The authors also tried to find out which physiological parameters, reflecting the activity of the muscular system and autonomic HR regulation are the best indicators of body response to potential life threat provoked in a simulated (virtual) environment.

\section{METHODS}

\section{Participants}

22 young healthy males aged $21-33$ years $(\mathrm{M}=24.3$, $\mathrm{SD}=2.8$ ) participated in the study. The participants were not professional drivers, but they had access to a car and used it regularly for their private activities. We have no detailed information on the years of their experience as drivers. On the day of the study, the participants did not consume any products containing caffeine and did not 
take any medication. During the stage of preparation for driving simulator tests, each participant stayed in the room next to the simulator for about $30 \mathrm{~min}$, assuming a seated position and was then informed about the goal and rules of the study.

\section{Place of the study}

The study was carried out at the Faculty of Transport of the Warsaw University of Technology. ECG and EMG signals were recorded during the test in a passenger car simulator "autoPW", used in the research to describe the driver's behavior in normal road traffic conditions and during accidents, e.g. a crash with other vehicles or sudden crossing of the road by a pedestrian $[18,19]$. The simulator is a static one. A part of it is an original car cabin with driver's seat. The simulator's interior is equipped with all devices a real vehicle is equipped with - pedals, turn signal indicator, speedometer, indicators and warning lamps.

The simulator is equipped with big projection screen. Its large size made the driver feel like in a real traffic situation. The vision angle was: horizontally $62^{\circ}$, vertically $42^{\circ}$ and the screen dimensions were $2.9 \times 2.14 \mathrm{~m}$ (horizontally $\times$ vertically).The accuracy of the reaction time measurements was $0.02-0.04 \mathrm{~s}$.

\section{Course of the test - study scenario}

The reaction assessment test in drivers comprised driving simulation in an urban setting according to the prepared scenario. This involved driving in the streets with three identically connected crossroads whose geometry was identical as in one of the Polish cities. The selected crossroads were known to have relatively frequent accidents. The driver had to observe all road traffic rules that are obligatory during real driving, including speed limitation to $50 \mathrm{~km} / \mathrm{h}$. The arrangement of road signs did not allow the driver to go beyond the preset route.

Prior to the test, all the participants were acquainted with the specifics of the passenger car driving simulator by performing a several-minute test drive. Each participant decided when to finish the test drive once they felt secure enough to start the simulator test. No participant had known the detailed course of the real test earlier. The test included a simulation of a sudden, unexpected crash, posing a potential threat to the driver's health. It involved another passenger car suddenly driving out of a side street from the driver's left or right side with high speed. The exact speed of the vehicle at the moment of the crash was not recorded. At the moment of the crash, the vehicle was on a straight road with a yield sign, hence the velocity was approximately $50 \mathrm{~km} / \mathrm{h}$. The crash was planned to occur in different crossroads, hence the crash time, counted from the moment of setting off, was not the same (about $20 \mathrm{~min}$ ) and it was unexpected for the participants. The persons observing the test assessed the changes in the driver's behavior in response to the accident; they were tracing the head and body tilt, turning of the steering wheel, pressing the gas or the brake pedal. The participants were not allowed to inform their colleagues about the course of the test. All tests were carried out before noon.

Examination stages:

1. Presenting the test course to the subjects.

2. Placement of electrodes (ECG and EMG).

3. Test of the ECG signal recording device at rest (seated position).

4. Test drive.

5. EMG record with maximal voluntary contraction (MVC) of muscles.

6. Driving ended with a crash.

7. Saving files with continuously recorded EMG signal in the computer.

8. Completion of recording the ECG signal.

\section{Physiological parameters}

ECG signal

ECG signal was recorded using the Holter method, which is non-invasive and does not interfere with the driver's 
activities. Medilog Oxford MR45 tape recorders were used for this purpose, equipped with real time path, enabling the reference of ECG signal epochs to the events described by the supervising examiner in the report on chrono-analysis. The recorders used and signal analysis system - Medilog Optima, Oxford Medical Systems met the requirements of HRV analysis established by the European Society of Cardiology and the North American Society of Pacing and Electrophysiology [20,21].

HRV analysis was carried out for ECG segments which were free from ventricular and supraventricular excitations. The data were obtained from the RR tachogram (ms). Power spectrum was determined by means of Fast Fourier Transformation (FFT). A HRV analysis was performed for 1-minute sequences of RR intervals following the assumption that in such circumstances as an unexpected crash there is a chance to grasp the short-term modulation of HR by ANS. This is in accordance with the assumption concerning the required signal stability. The commonly applied analysis of 2-5 min record would provide the already averaged values.

For 1-minute sequences of RR intervals, corresponding to various conditions: rest (seated position), undisturbed driving, crash (computer-recorded crash time corresponded to the beginning of the minute interval), after crash (seated position), 4 parameters reflecting HRV were determined in the time domain. These were: arithmetic mean of all RR intervals of the sinus rhythm (mRR (ms)), standard deviation (SD) of RR intervals [SDNN (ms)], square root of the mean squared differences of successive RR intervals, [rMSSD (ms)], percentage of pairs of successive RRs that differ by more than $50 \mathrm{~ms}$ [pNN50 (\%)]. HRV in the frequency domain was described using spectral power values in low frequency (LF) band: $\mathrm{LF}\left(\mathrm{ms}^{2}\right): 0.04-0.15 \mathrm{~Hz}$ and high frequency (HF) band: $\mathrm{HF}\left(\mathrm{ms}^{2}\right): 0.15-0.40 \mathrm{~Hz}$ as well as the $\mathrm{LF} / \mathrm{HF}$ ratio reflecting the sympathovagal balance. In the physiological interpretation, the mRR and SDNN values indicate changes in tone within the entire ANS in HR regulation. The rMSSD and pNN50 values are considered the indicators of the vagal tone. LF spectral power reflects mainly the sympathetic activity, while HF reflects parasympathetic activity in autonomic HR regulation.

\section{EMG signal}

MESPEC 3000 (Mega Electronics, Finland) device was used for the measurement. This device enables recording and observation of unprocessed EMG signals. The sensitivity of analyzer pre-amplifiers is $\pm 1 \mu \mathrm{V}$. EMG signal measurement is within the range of $\pm 5000 \mu \mathrm{V}$. The signal sampling frequency was $1 \mathrm{kHz}$. The program generates measurement results sheet using ASCII code.

For the EMG signal record, superficial electrodes MSOOS (Medicotes, Denmark) were used. Pre-amplifiers were placed next to the electrodes, enabling minimization of interference of the signal sampled by 12 bit transducer A/D with the sampling frequency of $1000 \mathrm{~Hz}$. Prior to the electrode placement, the subject's skin was adequately prepared (shaved, if necessary - cleaned using alcohol) so that the resistance between the skin and the electrode was below $2 \mathrm{k} \Omega$. During the test, EMG signals from $m$. flexor digitorum superficialis (FDS) and $m$. trapezius (TR) were recorded on the right and left side. Over each examined muscle three measuring electrodes were placed at the same distance from one another. Two electrodes were active (placed along muscle fibers), while the third was the reference electrode. The surface of the active electrode was $5 \times 5 \mathrm{~mm}$ (for each electrode) and the distance between the electrodes was $20 \mathrm{~mm}$.

During the first stage of EMG measurements, the signal was recorded during maximal muscle effort development. EMG signal measurements at maximal effort, performed separately for each of the studied muscles, were performed during short tests lasting for several minutes. For each of the studied muscles, two trials were performed 
at MVC. Next, EMG signal was measured for all 4 muscles during passenger car simulator test involving driving in urban setting and a crash.

For the assessment of changes in EMG signal, the amplitude was used with the values increasing proportionally to muscle excitation. For a given muscle, the mean EMG amplitude value, obtained at the moment of the crash, was divided by the amplitude value obtained from the measurement performed at MVC for the same muscle. This allowed for obtaining load values expressed in $\%$ of maximal voluntary contraction (\% MVC), corresponding to muscle activation during usual driving and crash. Reference of EMG signal to maximal effort enabled obtaining load measure that excluded the effect of individual factors, such as adipose tissue content or skin resistance on the analysis accuracy. The ratio of muscle activation during the crash to muscle activation during normal driving was also determined. RMS (root mean square) was accepted as EMG signal amplitude measure.

\section{Statistical Analysis}

The median and the range values (max-min) for all the variables in the group of 22 participants are compared in Table 1 and 2. In order to find out whether the values of the same variable significantly differ at different stages of the study, a nonparametric Friedman ANOVA test was used. For the comparison of the results obtained from two different stages of the study, the Wilcoxon signed-rank test was used. The correlation between different variables was assessed using Pearson correlation coefficient. The level of statistical significance was set at $\mathrm{p}<0.05$. Calculations were made using STATISTICA-6PL program.

Table 1. Heart rate variability (HRV) in the time and frequency domains in the sample of 22 males during the passenger car driving simulator tests

\begin{tabular}{|c|c|c|c|c|c|}
\hline \multirow[t]{2}{*}{ Variable } & \multicolumn{4}{|c|}{$\begin{array}{l}\text { Results of simulator tests } \\
\text { Median (min-max) }\end{array}$} & \multirow[t]{2}{*}{ ANOVA } \\
\hline & rest & driving & crash & after crash & \\
\hline $\mathrm{mRR}(\mathrm{ms})$ & $\begin{array}{c}673 \\
(531-888)\end{array}$ & $\begin{array}{c}627 \\
(462-893)\end{array}$ & $\begin{array}{c}616 \\
(484-828)\end{array}$ & $\begin{array}{c}658 \\
(502-860)\end{array}$ & $\mathrm{p}<0.0001$ \\
\hline SDNN (ms) & $\begin{array}{c}41.08 \\
(18.20-114.5)\end{array}$ & $\begin{array}{c}50.42 \\
(14.38-97.79)\end{array}$ & $\begin{array}{c}39.98 \\
(14.07-118.4)\end{array}$ & $\begin{array}{c}60.17 \\
(23.73-103.13)\end{array}$ & ns \\
\hline $\mathrm{rMSSD}(\mathrm{ms})$ & $\begin{array}{c}24.02 \\
(12.98-47.96)\end{array}$ & $\begin{array}{c}20.07 \\
(7.69-55.96)\end{array}$ & $\begin{array}{c}18.80 \\
(7.85-49.68)\end{array}$ & $\begin{array}{c}25.30 \\
(10.52-57.99)\end{array}$ & ns \\
\hline pNN50 (\%) & $\begin{array}{c}3.19 \\
(0-23.08)\end{array}$ & $\begin{array}{c}3.13 \\
(0.30)\end{array}$ & $\begin{array}{c}2.83 \\
(0-25)\end{array}$ & $\begin{array}{c}5.62 \\
(0-32)\end{array}$ & ns \\
\hline $\mathrm{LF}\left(\mathrm{ms}^{2}\right)$ & $\begin{array}{c}1082 \\
(236-5272)\end{array}$ & $\begin{array}{c}722 \\
(58.4-2964)\end{array}$ & $\begin{array}{c}656 \\
(118-3535)\end{array}$ & $\begin{array}{c}984 \\
(54-4046)\end{array}$ & ns \\
\hline $\mathrm{HF}\left(\mathrm{ms}^{2}\right)$ & $\begin{array}{c}207 \\
(44-988)\end{array}$ & $\begin{array}{c}241 \\
(9.8-1630)\end{array}$ & $\begin{array}{c}107.5 \\
(13-906)\end{array}$ & $\begin{array}{c}338 \\
(34-2165)\end{array}$ & ns \\
\hline $\mathrm{LF} / \mathrm{HF}$ & $\begin{array}{c}4.61 \\
(0.47-23.35)\end{array}$ & $\begin{array}{c}4.36 \\
(0.99-13.18)\end{array}$ & $\begin{array}{c}3.86 \\
(1.43-26.63)\end{array}$ & $\begin{array}{c}3.53 \\
(0.34-14.82)\end{array}$ & ns \\
\hline
\end{tabular}

mRR - arithmetic mean of all RR intervals of the sinus rhythm, SDNN standard deviation (SD) of RR intervals, rMSSD - square root of the mean squared differences of successive RR intervals, pNN50, percentage of pairs of successive RRs that differ by more than $50 \mathrm{~ms}$, LF - low frequency, HF - high frequency, LF/HF - sympathovagal balance.

ns - not significant. 
Table 2. Variables corresponding to the EMG signal from 2 muscle groups $m$. trapezius (TR) and $m$. flexor digitorum superficialis (FDS) for 21 participants in the passenger car driving simulator test

\begin{tabular}{lcccc}
\hline \multirow{2}{*}{ Variable } & \multicolumn{3}{c}{$\begin{array}{c}\text { Results of simulator tests } \\
\text { Median (min-max) }\end{array}$} & $\begin{array}{c}\text { Wilcoxon-test } \\
(1 \text { vs. } 2)\end{array}$ \\
\cline { 2 - 4 } & $\begin{array}{c}\text { crash } \\
(1)\end{array}$ & ratio & \\
\hline TR (\%MVC) & & & \\
left side & 4.5 & 6.6 & 1.7 & $\mathrm{Z}=2.777$ \\
& $(0.7-34.0)$ & $(1.6-58)$ & $(0.6-24.1)$ & $\mathrm{p}<0.005$ \\
right side & 3.9 & 6.8 & 2.3 & $\mathrm{Z}=3.506$ \\
& $(0.4-21.9)$ & $(0.7-51.6)$ & $(0.5-22.5)$ & $\mathrm{p}<0.0005$ \\
FDS (\%MVC) & & & \\
left side & 4.0 & 25.1 & 4.3 & $\mathrm{Z}=3.549$ \\
& $(0.2-11.8)$ & $(0.6-92.3)$ & $(0.7-62.3)$ & $\mathrm{p}<0.0004$ \\
right side & 4.7 & 21.4 & 3.9 & $\mathrm{Z}=3.593$ \\
& $(0.3-14.0)$ & $(0.3-95.1)$ & $(0.6-46.4)$ & $\mathrm{p}<0.0003$ \\
\hline
\end{tabular}

$\% \mathrm{MVC}$ - maximal voluntary contraction.

\section{ETHICS}

The study was approved by the Ethics Committee at the Central Institute for Labour Protection in Warszawa. All the participants were informed about the goal and course of the study and the physiological parameters recording techniques (ECG and EMG). All the subjects signed a written informed consent to participate in the study they could withdraw from it at any time without having to give a reason.

\section{RESULTS}

Table 1 presents the results of the statistical analysis of the variables reflecting HR in the time and frequency domains from the sample of 22 participants during different stages of the driving simulator test. The comparison of the results, obtained at different moments of the test using Friedman ANOVA analysis, showed statistically significant differences in the $m R R$ variable $\left(c^{2}=25.860, p<0.0001\right)$. The results of the HRV analysis in the time and frequency domains are presented in a graphic form in Figure 1 and 2. Statistically significant differences between the results, obtained during the crash and in other conditions during the driving simulator test are marked. The Wilcoxon signed-rank test showed significant differences in the results recorded during the crash compared to the results obtained after the crash for $\mathrm{mRR}$ variables $(Z=3.199, p<0.0014)$, $\operatorname{rMSSD}(Z=2.455$, $\mathrm{p}<0.014)$. For these variables, the results recorded after the crash differed from the results obtained at rest, respectively at the level $\mathrm{p}<0.0001(\mathrm{Z}=4.015)$ and $p<0.03(Z=2.172)$. The results of HRV analysis in the time domain indicate that during the crash a decrease in $\mathrm{mRR}$, rMSSD, and pNN50 was noted as well as an increase in SDNN compared to the obtained during easy driving, but the differences turned out statistically insignificant (Figure 1).

The comparison of the values reflecting HRV in the frequency domain during and after the crash using the Wilcoxon signed-rank test revealed significant differences in spectral power in LF and HF bands at the level $p<0.024$ $(\mathrm{Z}=2.254)$. Compared to the previous undisturbed driving, the crash did not result in significant spectral power 

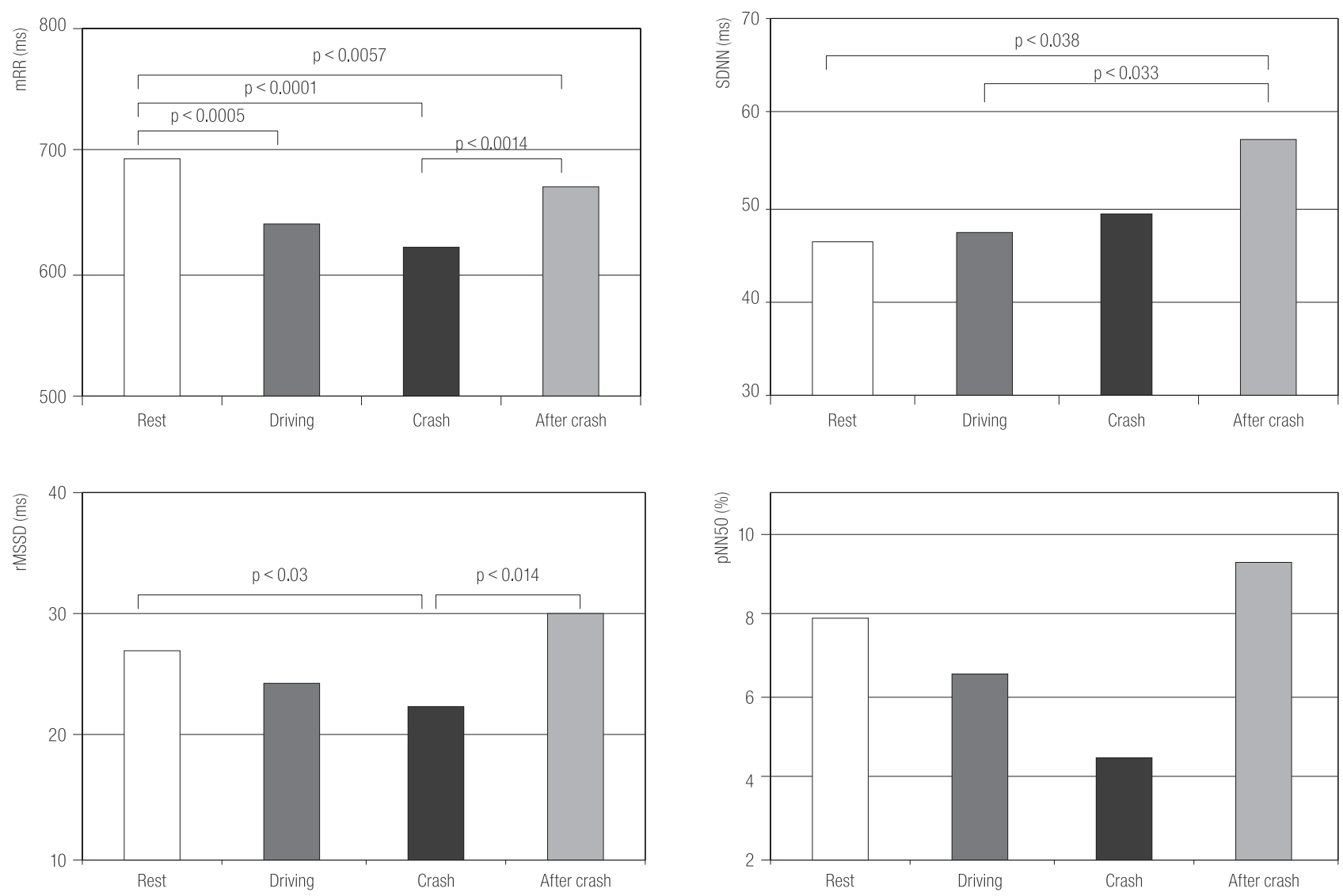

mRR - arithmetic mean of all RR intervals of the sinus rhythm, SDNN - standard deviation of RR intervals, rMSSD - square root of the mean squared differences of successive RR intervals, pNN50 - percentage of pairs of successive RRs that differ by more than $50 \mathrm{~ms}$.

Fig. 1. Values of the parameters reflecting heart rate variability (HRV) in the time domain at different moments of experimental driving on a passenger car driving simulator in the sample of 22 drivers

changes in LF and HF and in the LF/HF ratio. An increase in the sympathovagal balance, although statistically insignificant, was observed, which suggested an increase in the ANS sympathetic component of HR regulation. It was probably due to the decrease in parasympathetic component activity, expressed by a significant $(p<0.03)$ increase in the rMSSD value, with no changes in sympathetic activity, expressed by the spectral power in LF frequency band (Figure 2).

Table 2 presents the comparison of statistical analysis results, i.e. the variables reflecting changes in the EMG signal in the sample of 21 drivers during different stages of the driving simulator test. The results obtained from one subject were excluded due to the abnormalities in the EMG signal record. During the crash, a statistically significant increase in MVC of both muscle groups namely $m$. trapezius (TR) and $m$. flexor digitorum superficialis (FDS) on the right and left side was noted compared to undisturbed driving (Table 2, Figure 3). The comparison of MVC percentage during the crash and throughout undisturbed driving for both groups of muscles - TR and FDS on the right and left side using the Wilcoxon signed-rank test showed statistically significant differences. The MMVC value before and during the crash indicates stronger responses from FDS than from TR on the right and left side (Table 2). 

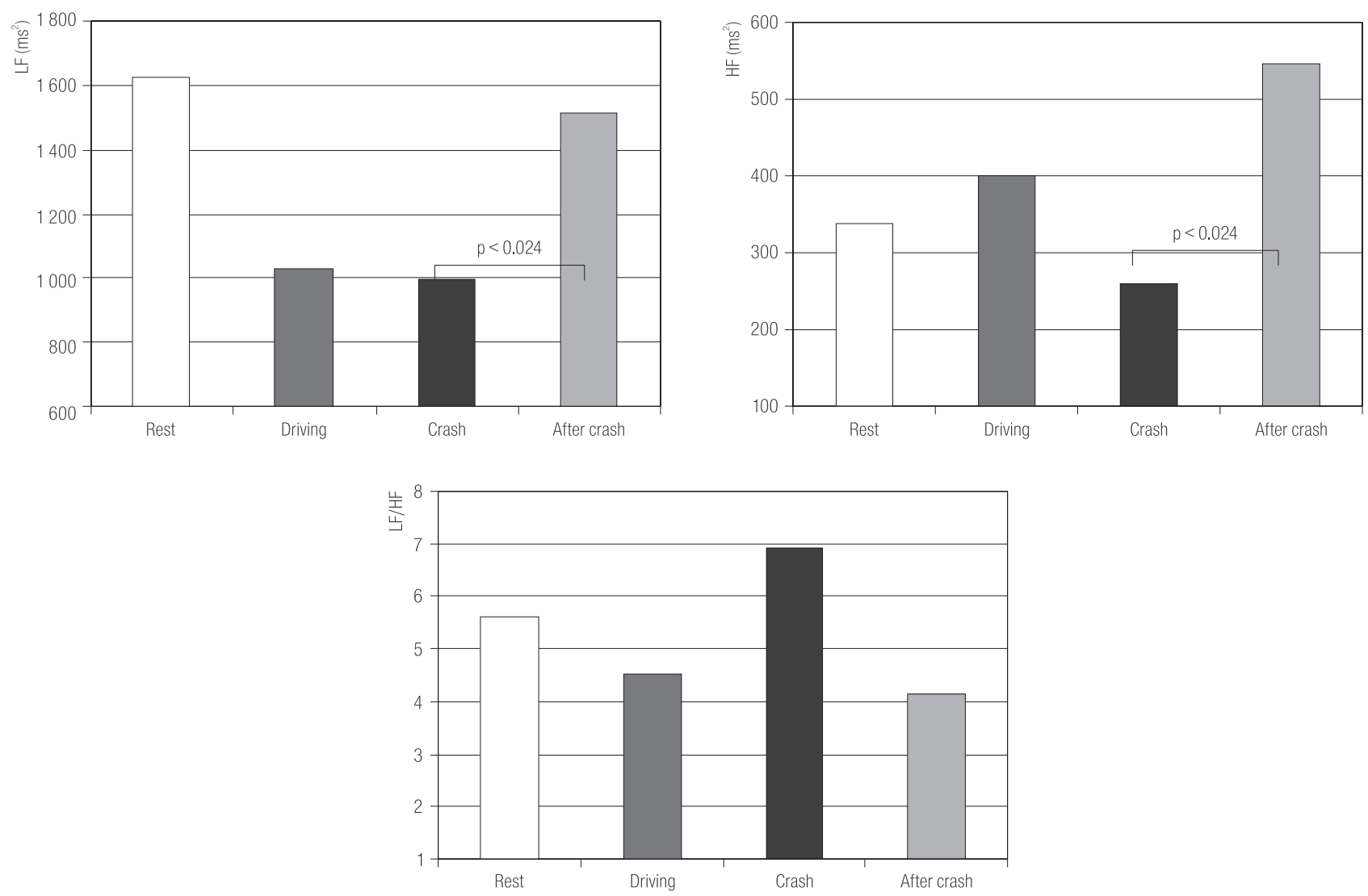

$\mathrm{HF}$ - high-frequency power of RR intervals, LF - low-frequency power of RR intervals, LF/HF - ratio of low-frequency to high-frequency power.

Fig. 2. Parameters reflecting heart rate variability (HRV) at different moments of the simulator driving test in the sample of 22 drivers

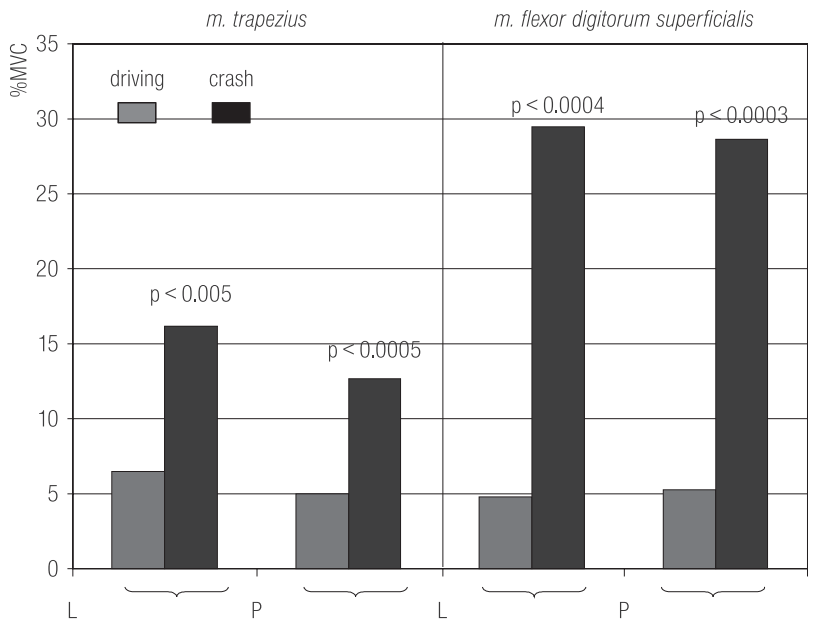

L - left side; $\mathrm{P}$ - right side.

Fig. 3. Values of TR and FDS muscle contraction median expressed by root mean square (RMS) amplitude (\%MVC) in the group of 21 participants performing the driving simulator test
For each ECG and EMG signal, a parameter was selected with values indicating the most pronounced response connected with the crash in 21 subjects performing the driving simulator test. The correlation coefficient between the length of RR intervals (mRR) during the crash and the ratio of EMG amplitude signal values, obtained prior to the crash, to the analogical values obtained during the crash for $m$. flexor digitorum superficialis of the left arm (FDS-L) was calculated. A significant correlation was found $(r=-0.4496$, $\mathrm{p}<0.05)$, indicating that during the crash shorter RR corresponded to higher values of the amplitude ratio (Figure 4).

Since no behavioral response, such as steering wheel turning or head or body tilt, was noted in a part of 


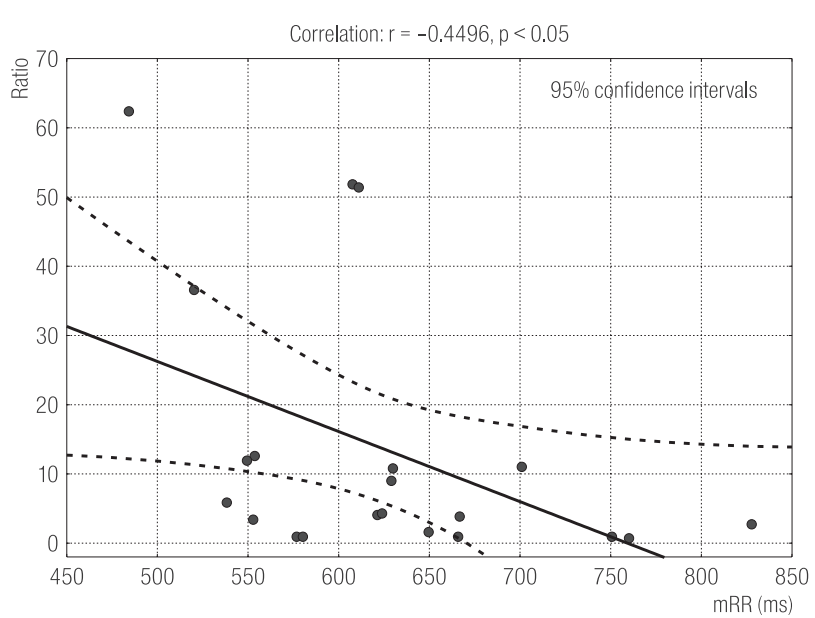

Fig. 4. Correlation between the mean RR interval (mRR) during the crash and the ratio of the EMG signal amplitude before the crash to the EMG signal amplitude during the crash (ratio) for $m$. flexor digitorum superficialis left side (FDS-L) in the group of 21 subjects performing the driving simulator test

the participants during the driving simulator test, individual physiological responses, expressed by the variables: mRR, HF, LF and RMS for FDS-L and FDS-P were analyzed. The authors concluded that these variables reflected best the circulatory and musculoskeletal system responses to a simulated road crash in the presented study. Individual values obtained during driving and the crash are presented in Figure 5. Such results indicated that responses from the circulatory and musculoskeletal systems did not occur in all the participants.

Analysis of the changes in mRR and RMS, observed in the FDS-L muscle during the crash, in the light of the values corresponding to driving prior to the crash in the sample of 21 subjects made the authors conclude that in 10 cases, the changes occurred simultaneously in the circulatory and musculoskeletal system. In seven cases, the crash did not contribute to any changes in the length of RR intervals (mRR), while a response from the FDS muscle was noted at the left and right side. In four cases, reductions of RR intervals (mRR) were not accompanied by visible changes in RMS.
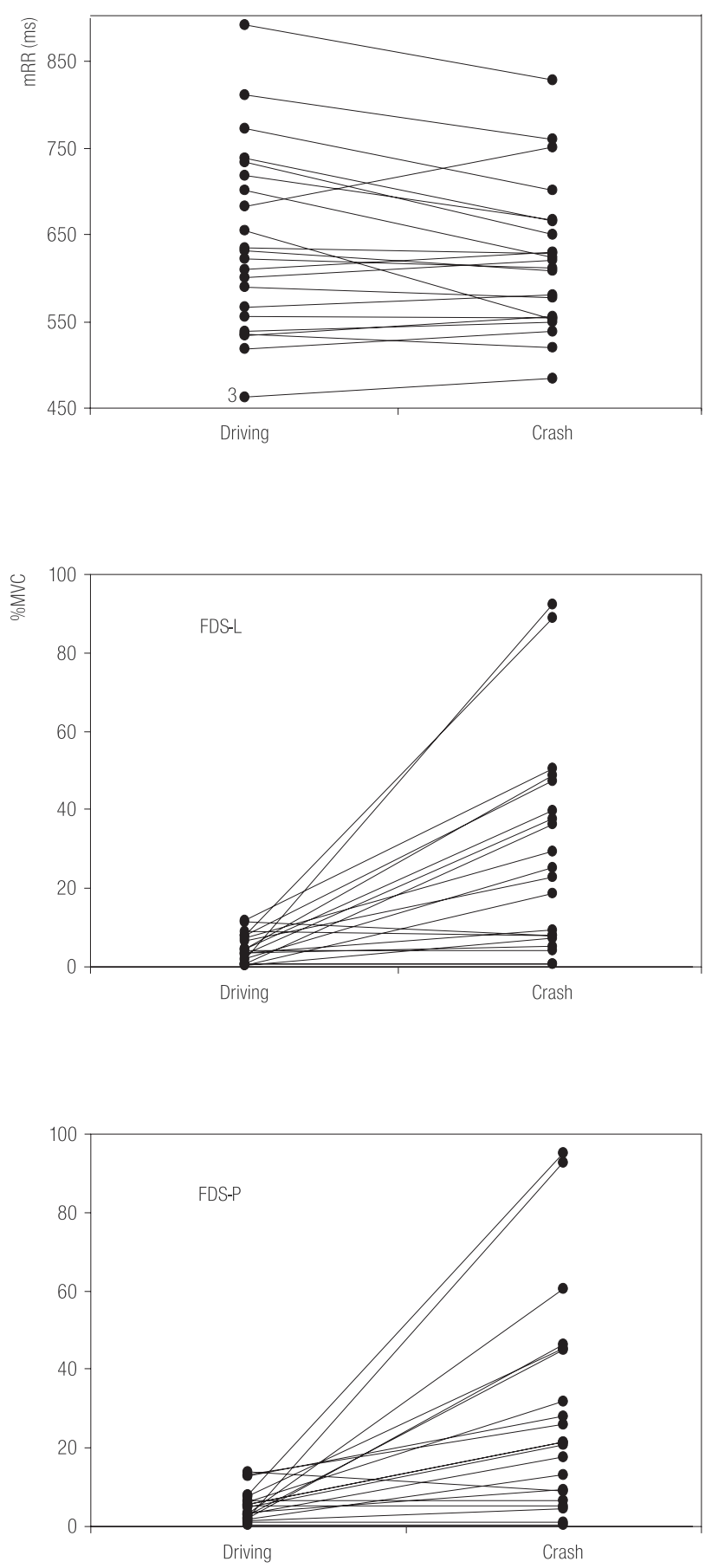

Results of each individual subject are connected with a line. $\mathrm{L}$ - left side; $\mathrm{P}$ - right side.

Fig. 5. Individual changes in the mean length of RR intervals (mRR) and the $m$. flexor digitorum superficialis (FDS) contraction during easy driving and the crash in 21 subjects performing the driving simulator test 


\section{DISCUSSION}

The study involved an analysis of physiological parameters which were determined based on noninvasive measurements. Two physiological signals - ECG and EMG were continuously measured using the recording techniques that did not interfere with driving to avoid an additional factor that might negatively affect the driver's attention level.

A crash in road traffic may result in acute stress. It evokes e.g. changes in autonomic HR regulation, revealed by the HRV analysis in the time and frequency domains, described in this paper. Riediker et al., in their case report, described changes in the ECG record obtained from a policeman with a Holter device attached at the moment he learned about the terrorist attack on 11 September. Acute emotional stress connected with this event resulted in changes in the ECG record, which had not been noted in this participant before in other stressful situations during ECG signal record. The HRV analysis showed a decrease in the percentage of RR intervals, differing by more than $50 \mathrm{~ms}$ (pNN50), which indicated cessation of parasympathetic activity and an increase in the SDNN parameter value, suggesting a significant increase in sympathetic activity [22].

During a simulated crash, in our examinations, an increase in HR was noted in the participants, expressed by a significant reduction of RR intervals. The SDNN value increased compared to that obtained under conditions of easy driving, the difference, however, turned out statistically insignificant. The observed increase in the sympathovagal balance indicated the increase in sympathetic activity (insignificant). Higher values of the sympathovagal balance did not result from the changes in sympathetic activity, because a decrease was noted in the spectral power in the LF band and in the SDNN parameter value (insignificant). The apparent yet insignificant increase in sympathetic predominance was probably due to a decrease in parasympathetic activity, indicated by the decremental tendency of spectral power in the HF band (Figure 2).
ECG and EMG signals are used for the assessment of fatigue in drivers working in public transport. The reasons entailing fatigue during vehicle driving include long duration of performing the same activity [23,24], too short sleep period [24,26,27], weariness while driving [27] as well as environmental factors (vibration, noise and too high temperature) $[28,29]$.

Statistical analysis of road accidents suggests that there are good reasons to regard fatigue as one of the basic causes of road accidents [28,30-34]. Fatigue may result from excess load due to static work and mental load (overload or monotony) [35-37]. The effect of mental load on the musculoskeletal system can be observed especially in the case of work performed using relatively low strength when the task is monotonous and/or the activities are repeated [38,39], which is observed during sustained vehicle driving. In the presented study, this problem did not occur as the testing time was short - about $20 \mathrm{~min}$ and the muscle tone during normal driving was about 4-5\% MVC and only during the crash it increased to over 20\% MVC (Table 2).

The physiological responses (e.g. gripping the steering wheel tight) and the mental responses (tracking the traffic and making decisions to drive safely) to muscle tone are believed to be different. Results of some studies indicate that both types responses evoke similar responses, while other studies suggest that responses vary, depending on the kind of physical and mental tension in a given test [17]. The increased contraction of Trapesius muscle was revealed by the EMG record in the subjects performing various psychomotor tasks [40]. The test assessing muscle activity during work performed at a computer work station revealed higher activity of the upper trapezius muscle at the side opposite to the computer mouse [41]. During simulated driving in an urban setting in our experiments, muscle activity was connected with steering wheel movements, during gear change or switching on the direction indicator were mainly connected with right side muscles activation. 
This study found that the crash resulted in a significant increase in the contraction of $m$. flexor digitorum superficialis and $m$. trapezius on both sides. The EMG signal amplitude ratio of the values obtained before the crash and during the crash was higher for $m$. flexor digitorum superficialis on the left side (FDS-L) and $m$. trapezius on the right side (TR-P). It is difficult to determine whether this phenomenon was due to the driver's emotional condition or work performed.

During the 30-minute driving simulator test, a driver was not affected by physical environmental factors, such as tremor, temperature, noise or acceleration. The microclimate inside the simulator room met comfort requirements. The test duration was too short to allow such factors as driver's fatigue after many hours of driving or monotony to influence the driver's responses during a simulated crash. However, fatigue should not be ignored. It was an uncontrolled factor, resulting from the fact that the test followed many hours of everyday activity since it took place in the late afternoon.

Some recent studies indicate that the discomfort due to simulator sickness might have been an aggravating factor $[42,43]$. No history of motion sickness was taken from the participants, therefore it was impossible to predict their susceptibility to simulator disease.

Upon completion of the test, some participants reported such symptoms as nausea, headache, dizziness and balance disorders; this finding justifies the need for examining such history in future studies using driving simulators. The studies using driving simulators indicate that susceptibility to motion sickness affects the HRV values in the subjects. Another study (43) found that the subjects prone to motion sickness, compared to other subjects, experienced HR slowing, manifested by longer RR intervals and a significant decrease in the sympathovagal balance (LF/HF) after 30 min forklift truck driving. In the studied sample, the observed changes in spectral power values in $\mathrm{HF}$ and $\mathrm{LF}$ bands were statistically insignificant, but indicated a simultaneous increase in ANS sympathetic and parasympathetic activity with significantly decreasing sympathetic activity [43].

In the present study, the crash took place after 20 min of driving, thus we may suspect that if the sample included the subjects with motion sickness, this might have affected their heart rate through changes in sympathetic and parasympathetic activity. As a consequence, it might have also affected the results reflecting the response from autonomic HR regulation mechanisms to crashrelated stress.

HRV parameters are sensitive to different kinds of emotional or mental load [15]. A simulated crash and the resulting life threat were not such a load as analogical circumstances in real road traffic. The test participants were certainly aware of this fact. The lack of behavioral response from some of the participants may indicate the lack of imagination since the drivers did not realize the consequences of the crash under real conditions. Real conditions may modify the obtained results concerning both signals - ECG and EMG. In the case of the EMG signal, physical factors, e.g. tremor, may significantly affect muscle contractions in drivers [29].

The selection of male subjects was reasonable since research has shown that in women, the menstrual phase affects HRV, causing significant changes in the LF and HF spectral power and changes in the LF/HF ratio in the follicular phase compared to the luteal phase $[44,45]$.

Due to varied fatigue effects, changing requirements concerning the performed tasks and external sources of stress as well as individual differences, the attempts to use ECG and EMG signals to determine the driver's contribution to road accidents did not bring about the expected outcome $[36,37,46,47]$. However, further search of effective approaches to prevent road accidents in case of professional and amateur drivers is essential for the improvement of driver's safety and reduction of financial and social costs including treatment costs or disability benefits 
and the cost of environmental pollution (accidents of vehicles transporting chemicals).

The study results indicate that one parameter, e.g. HR is insufficient to assess physiological changes in the cardiovascular system. The HRV analysis may potentially overcome the limitation resulting from the fact that different modes of ANS control may reflect different ways of reacting to physiological factors $[10,15,16]$. The assessment of driver's workload using physiological parameters is believed to be a valuable approach [16].

\section{CONCLUSIONS}

Such parameters as mRR (ECG signal) and FDS-L amplitude (EMG signal) turned out most sensitive to accident risk.

During the incidents, changes in ECG and EMG were simultaneous in half of the cases.

The results indicate that a more complete assessment of drivers' responses to crashes in road traffic can be obtained based on registering parallel records of these two physiological signals ECG and EMG.

\section{ACKNOWLEDGMENTS}

We would like to thank the staff of the Virtual Safety Engineering and Biomechanics Lab (ViSEB), Institute of Aeronautics and Applied Mechanics, Faculty of Power and Aeronautical Engineering, Warsaw University of Technology, for their participation in the study.

\section{REFERENCES}

1. Jones CB, Dorrian J, Rajaratnam SMW. Fatigue and the criminal law. Ind Health. 2005;43(1):63-70, http://dx.doi. org/10.2486/indhealth.43.63.

2. Arndt R. Workplace, stress, and cumulative trauma disorders. J Hand Surg. 1987;12(5 Pt 2):866-9.
3. Konarska M, Stewart R, McCarty R. Sensitisation of sympathetic adrenal modularly responses to a nevel stressor in chronical stressed laboratory rats. Physiol Behav. 1989;46(2): 129-35, http://dx.doi.org/10.1016/0031-9384(89)90245-X.

4. Konarska M. [Development of the psychophysiological concept of environmental stress]. Med Srod. 2002;5(1):5-15. Polish.

5. Duque J, Masset D, Malchaire J. Evaluation of handgrip force from EMG measurements. Appl Ergon. 1995;26(1): 61-6, http://dx.doi.org/10.1016/0003-6870(94)00003-H.

6. West W, Hicks A, Clements L, Dowling J. The relationship between voluntary electromyogram, endurance time and intensity of effort in isometric handgrip exercise. Eur J Appl Physiol. 1995;71(4):301-5, http://dx.doi.org/10.1007/BF00240408.

7. Cook T, Rosencrance J, Zimmermann C, Gerleman D, Ludewig P. Electromyographic analysis of a repetitive hand gripping task. Int J Occup Saf Ergon (JOSE). 1998;4(2): 185-200.

8. Bartuzi P, Roman-Liu D, Tokarski T. A study of the influence of muscle type and muscle force level on individual frequency bands of the EMG power spectrum. Int J Occup Saf Ergon (JOSE). 2007;13(3):241-54.

9. Roman-Liu D, Konarska M. Characteristics of power spectrum density function of EMG during muscle contraction below 30\% MVC. J Electromyogr Kinesiol. 2009;19(5): 864-74, http://dx.doi.org/10.1016/j.jelekin.2008.05.002.

10. Berntson GG, Cacioppo JT, Quigley KS. Autonomic determinism: The modes of autonomic control, the doctrine of autonomic space, and the laws of autonomic constraint. Psychol Rev. 1991;98(4):459-87, http://dx.doi.org/10.1037/0033295X.98.4.459.

11. Collins S, Karasek R. Reduce Vagal cardiac control variance in exhausted and high strain job subjects. Int J Occup Med Environ Health. 2010;23(3):267-78, http://dx.doi. org/10.2478/v10001-010-0023-6.

12. Sekiguchi C, Handa Y, Goth M, Kurihara Y, Nagasawa Y, Kuroda I. Frequency analysis of heart rate variability under flight conditions. Aviat Space Environ Med. 1979;50(6):625-34. 
13. Akselrod S, Gordon D, Ubel FA, Shannon DC, Barger AC, Cohen RJ. Power spectrum analysis of heart rate fluctuation: a quantitative probe of beat-to-beat cardiovascular control. Science. 1981;213(4504):220-2, http://dx.doi.org/10.1126/science.6166045.

14. Steptoe A, Vogele C. Methodology of mental stress testing in cardiovascular research. Circulation. 1991;83(4 Suppl):II14-24.

15. Backs RW. A comparison of factor analytic methods of obtaining cardiovascular autonomic components for the assessment of mental workload. Ergonomics. 1998;41(5):733-45, http://dx.doi.org/10.1080/001401398186883.

16. Backs RW, Lenneman JK, Wetzel JM, Green P. Cardiac measures of driver workload during simulated driving with and without visual occlusion. Hum Factors. 2003;45(4):525-38, http://dx.doi.org/10.1518/hfes.45.4.525.27089.

17. Wasmund WL, Westerholm EC, Watenpaugh DE, Wasmund SL, Smith ML. Interactive effects of mental and physical stress on cardiovascular control. J Appl Physiol. 2002;92(5):1828-34.

18. Lozia Z. [Driving simulators]. Warszawa: Wydawnictwa Komunikacji i Łączności; 2008. Polish.

19. Jurecki RS, Jaskiewicz M, Guzek M, Lozia Z, Zdanowicz P. Driver's reaction time under emergency braking a car - research in a driving simulator. Eksploat Niezawodn Mainten Reliab. 2012;14(4):295-30.

20. Pinna GD, Maestri R, Di Cesare A, Colombo R, Minuco G. The accuracy of power-spectrum analysis of heartrate variability from annotated RR list generated by Holter systems. Physiol Meas. 1994;15(2):163-79, http://dx.doi. org/10.1088/0967-3334/15/2/006.

21. Task Force. Heart rate variability: standards of measurement, physiological interpretation and clinical use. Task Force of the European Society of Cardiology and the North American Society of Pacing and Electrophysiology. Circulation. 1996;93(5): 1043-65, http://dx.doi.org/10.1161/01.CIR.93.5.1043.

22. Riediker M, Herbst MC, Devlin RB, Griggs TR, Bromberg PA, Cascio WE. Effect of the september 11, 2001 terrorist attack on a state highway patrol trooper's heart rate variability. Ann Noninvasive Electrocardiol. 2005;10(1):83-5, http://dx.doi.org/10.1111/j.1542474X.2005.00612.x.

23. Brown ID, Ticker AH, Simmonds DCV. Effect of prolonged driving on overtaking criteria. Ergonomics. 1970;13(2): 239-42, http://dx.doi.org/10.1080/00140137008931137.

24. Hakkanen J, Summala H. Fatal traffic accidents among trailer truck drivers and accident causes as viewed by other truck drivers. Accid Anal Prev. 2001;33(2):187-96, http://dx.doi. org/10.1016/S0001-4575(00)00030-0.

25. Sagberg F. Road accidents caused by drivers falling asleep. Accid Anal Prev. 1999;31(6):639-49, http://dx.doi. org/10.1016/S0001-4575(99)00023-8.

26. Fell DL, Black B. Driver fatigue in the city. Accid Anal Prev. 1997;29(4):463-9, http://dx.doi.org/10.1016/S00014575(97)00025-0.

27. Reyner LA, Horne JA. Falling asleep while driving: are drivers aware of prior sleepiness? Int J Med. 1998;11(3):120-3.

28. McDonald N. Fatigue, safety and the truck driver. London: Taylor \& Francis; 1984.

29. El Falou W, Duchene J, Grabisch M, Hewson D, Langeron Y, Lino F. Evaluation of driver discomfort during longduration car driving. Appl Ergon. 2003;34(3):249-55, http:// dx.doi.org/10.1016/S0003-6870(03)00011-5.

30. Åkerstedt T. Work hours and slippiness. Clin Neurophysiol. 1995,25(6):367-75, http://dx.doi.org/10.1016/09877053(96)84910-0.

31. Haworth NL, Heffernan CJ, Horne EJ. Fatigue in track accidents (rep. no. 3). Melbourne (Australia): Victorian Road Freight Industry Council; 1989.

32. Hamelin P. Lorry driver's time habits in work and their involvement in traffic accidents. Ergonomics. 1987;30(9):132333, http://dx.doi.org/10.1080/00140138708966026.

33. Mackie RR, Miller JC. Effects of hours of service, regularity of schedules, and cargo loading on truck and bus driver fatigue (Human Factors Research, Inc. Technical Report No. 1765-F). Washington, DC: Department of 
Transportation. Bureau of Motor Carrier Safety, FHWA, and National Highway Traffic Safety Administration; 1978.

34. Zuzewicz K, Konarska M, Luczak A. Injured professional drivers in Poland - an analysis of the causes and effects in relation to the time of the road accident. Int J Occup Saf Ergon (JOSE). 2010;16(1):81-91.

35. Davson D, Fletcher A. A quantitative model of work-related fatigue: Background and definition. Ergonomics. 2001;44(2):144-63, http://dx.doi.org/10. 1080/00140130119399.

36. Lal SKL, Craing A. Driver fatigue: Electroencephalography and psychological assessment. Psychophysiology. 2002;39(3):1-9, http://dx.doi.org/10.1017/ S0048577201393095.

37. Lal SKL, Craig A, Boord P, Kirkup L, Nguyen H. Development of an algorithm for an EEG-based driver fatigue countermeasure. J Saf Res. 2003;34(3):321-8, http://dx.doi. org/10.1016/S0022-4375(03)00027-6.

38. Bongers PM, Kremer AM, ter Laak J. Are psychosocial factors, risk factors for symptoms and signs of the shoulder, elbow, or hand/wrist? A review of the epidemiological literature. Am J Ind Med. 2002;41(5):315-42, http://dx.doi. org/10.1002/ajim.10050.

39. Van Galen GP, Müller ML, Meulenbroek RG, van Gemmert AW. Forearm EMG response activity during motor performance in individuals prone to increased stress reactivity. Am J Ind Med. 2002;41(5):406-19, http://dx.doi.org/10.1002/ ajim.10051.

40. Schleifer LM, Spalding TW, Kerick SE, Cram JR, Ley R, Hatfield BD. Mental stress and trapezius muscle activation under psychomotor challenge: A focus on EMG gaps during computer work. Psychophysiology. 2008;45(3):356-65, http://dx.doi.org/10.1111/j.14698986.2008.00645.x.
41. Wahlstrom J, Lindegard A, Ahlborg G, Ekman A, Hagberg M. Perceived muscular tension, emotional stress, psychological demands and physical load during VDU work. Int Arch Occup Environ Health. 2003;76(8):584-90, http:// dx.doi.org/10.1007/s00420-003-0454-5.

42. Money KE, Lackner JR, Cheung RSK. The Autonomic Nervous System and Motion Sickness. In: Milles BJ, Miller AD, editors. Vestibular Autonomic Regulation. New York, London, Tokyo: CRC Boca Raton; 1996. p. 147-73.

43. Zuzewicz K, Saulewicz A, Konarska M, Kaczorowski Z. Heart rate variability (HRV) and motion sickness during forklift simulator driving. Int J Occup Saf Ergon (JOSE). 2011;17(4):403-10.

44. Bonnemeier H, Richardt G, Potratz J, Wiegand UK, Brandes A, Kluge N, et al. Circadian profile of cardiac autonomic nervous modulation in healthy subjects: differing effects of aging and gender on heart rate variability. J Cardiovasc Electrophysiol. 2003;14(8):791-9, http://dx.doi. org/10.1046/j.1540-8167.2003.03078.x.

45. Xiaopeng B, Jingxiu L, Lingqi Z, Xueqi L. Influence of the menstrual cycle on nonlinear properties of heart rate variability in young women. Am J Physiol Heart Circ Physiol. 2009,297(2):H765-74, http://dx.doi.org/10.1152/ajpheart.01283.2008.

46. Desmond PA, Matthews G. Implications of task-induced fatigue effects for in-vehicle countermeasures to driver fatigue. Accid Anal Prev. 1997;29(4):515-23, http://dx.doi. org/10.1016/S0001-4575(97)00031-6.

47. Hartley L, Horberry T, Mabbott N, Krueger G. Report National Road Transport Commission: Review of Fatigue Detection and Prediction Technologies - September 2000. Virginia, Melbourne: Institute for Research in Safety and Transport, Murdoch University, Western Australia and Ergonomics Consultants; 2000.

This work is available in Open Access model and licensed under a Creative Commons Attribution-NonCommercial 3.0 Poland License - http://creativecommons.org/ licenses/by-nc/3.0/pl/deed.en. 